\title{
Can visual familiarity influence attitudes towards brands? An exploratory study of advergame design and cross-cultural consumer behaviour
}

\author{
Vanissa Wanick ${ }^{\mathrm{a}^{*}}$, James Stallwood ${ }^{\mathrm{b}}$, Ashok Ranchhodc, Gary Wills ${ }^{\mathrm{d}}$ \\ ${ }^{a}$ Winchester School of Art (WSA), University of Southampton, Park Ave, Winchester, Hampshire, SO23 8DL, UK; \\ +44 (0) 238059 6900; v.w.vieira@soton.ac.uk \\ ${ }^{b}$ Winchester School of Art (WSA), University of Southampton, Park Ave, Winchester, Hampshire, SO23 8DL, UK; \\ +44 (0) 238059 6900; J.E.Stallwood@soton.ac.uk \\ ${ }^{c}$ Winchester School of Art (WSA), University of Southampton, Park Ave, Winchester, Hampshire, SO23 8DL, UK; \\ +44 (0) 238059 6900; a.ranchhod@soton.ac.uk \\ ${ }^{d}$ Electronics and Computer Sciences (ECS), University of Southampton, University Rd, Southampton, SO17
} 1BJ, UK; +44 (0) 238059 2831; gbw@ecs.soton.ac.uk

${ }^{*}$ Corresponding author

\begin{abstract}
This paper aims to investigate the relationship between advergame design, advergame experience and consumer behaviour across cultures. For this purpose, a study was designed to compare and contrast behaviour patterns across Brazilian and British cultures. An advergame (Colheita de Café (CC)), featuring the Fairtrade mark was developed through a semiotics approach. Participants from both Brazil $(\mathrm{N}=30)$ and the UK $(\mathrm{N}=34)$ were invited to play the advergame and answer a questionnaire before and after gameplay. The results indicate that Brazilians felt more familiar with the visual elements incorporated by the advergame when compared to British consumers. Brazilians also had more favourable attitudes towards the brand, suggesting that visual familiarity could influence consumer behaviour. Contrary to our expectations, both Brazilian and British respondents had the same attitudes towards the advergame, showing that visual familiarity did not particularly influence the advergame experience. The main contribution of this paper is the suggestion that visual familiarity could influence consumer behaviour across cultures. We expect that our findings can be used in future research that examines cultural nuances in advergame design.
\end{abstract}


Keywords: advergames; culture; Brazil; UK; cross-cultural HCI; semiotics

\section{Highlights:}

- Consumers showed differences in visual familiarity.

- Game scenario, colour scheme and game objects evoke a sense of visual familiarity.

- Brand familiarity mediates implicit attitudes towards the brand.

\section{Introduction}

In the engagement economy, getting the attention of the consumer is not enough. Today, there is a focus on strategies that could evoke consumer engagement and promote a lasting relationship between consumer and brands. Games can strengthen brand associations, creating conditions that support product placement [1] and product engagement through interactivity. Advergames are one possibility for building stronger links with consumers. Advergames, as a combination of the words "advertising" and "gaming", are games designed around a persuasive message, usually sponsored by a brand [2]. However, the main challenge for advergame design is to promote meaningful experiences for consumers, since positive game experiences have a positive impact on brand attitudes [3]. Advertisers also need to look at the influence of interactive experiences in consumer engagement on a global scale as people across cultures often have different values and beliefs [4].

Research in advergames has looked at the influence of the characteristics of the brand and the game in terms of a consumer's psychological aspects, such as leaning, emotions, intentions to buy and behavioural responses such as recommendations or sharing the message with friends [5]. However, in a global world, the impact of advertising on consumer behaviour does not occur in a vacuum. Hence, the understanding of culture is crucial, since culture is a reflection of a composition of shared values, patterns and meanings within a group [6]. Therefore, the opportunities to study advergames in a cultural setting are huge. 
People from different cultures perceive advertising messages in different ways [7].

Generally, studies that investigate the influence of culture in advertising effectiveness and consumer behaviour tend to focus on the role of cultural dimensions, mostly inspired by the work of Hofstede, Hall and Schwartz [8]. Hall's dimensions of low vs. high context cultures in communications were used in advertising research [9]. For example, highcontext cultures (e.g. Japanese, Arabic, Latin American, French and Italian) tend to value nationalist and patriotic brand imagery in advertising messages, if compared to lowcontext cultures (e.g. Swiss, German, Scandinavian and English) [9]. Thus, advertising design influences people's perceptions about a brand, particularly if considering their cultural background. Since advergames are a form of advertising via games, the same principles might be applicable.

Latin America is living an intense transformation. As mentioned in a report from McKinsey Global Institute [10], countries like Brazil are living in a recessionary environment, plagued by political crises that affects the way consumers decide to buy products and services. Yet, there is little research dedicated to a wider understanding of Latin American countries in this sector, particularly in Brazil, which is the biggest country in South America and one of the largest markets for digital games, commanding 35\% of the worldwide gaming market [11].

Research in consumer behaviour across cultures has mainly focused on nuances between individualistic and collectivist cultures, particularly comparing Eastern and Western nations [12]. This opens an opportunity for other cross-cultural comparisons, such as studies involving Latin American countries like Brazil. When studies of advergames across cultures are undertaken, research shows that compared to Americans, Hispanic players have a more favourable attitude towards advergames that are more negatively viewed in the developed nations [13]. This indicates that if people from different cultures have different attitudes towards an advergame, it is possible that they are influenced by their cultural values and the design of the advergame.

Another aspect to be considered is the influence of overall gameplay experience on brand attitudes. Players who feel more immersed in advergames tend to have more positive attitudes towards the brand [3]. The level of interactivity of the advergame [14] and the integration between the game and the brand [13] also play an important part in brand 
attitudes. Thus, there is a connection between advergame experience and consumer behaviour, which would be influenced by the way the advergame was designed and developed.

Taking the above discussion into consideration, the research question that guided this study is:

- What is the connection between advergame design, advergame experience and consumer behaviour, when comparing Brazil and UK consumers?

In order to address this question, we analyse the current literature in cross-cultural games, cross-cultural advertising, cross-cultural Human-Computer Interaction (HCI) principles and the cultural dimensions from both Brazil and the UK. After this review, an advergame sponsoring Fairtrade coffee using specific design manipulations was developed followed by a questionnaire designed to measure the influence of advergame design on consumer behaviour. The main objectives of this study are to:

- Explore the connection between advergame design, advergame experience and consumer behaviour across cultures (in that case Brazil and the UK)

- Compare the attitudes from Brazilian and British consumers after gameplay

- Understand the main principles of advergame design that could be used to influence advergame experience and brand attitudes for Brazilian and British consumers

The next section addresses the research background and the main constructs that supported the theoretical framework proposed by this research.

\section{Research background}

In order to address our research question, we started by analysing three main areas of the literature: (1) advergame experience and consumer behaviour, looking at main determinants of the influence of gameplay in consumer behaviour, (2) cross-cultural advergames, including aspects that influence the design of games across cultures and comparative studies in Human-Computer Interaction (HCI) that could give us main elements to advergame design, and (3) the cultural characteristics of Brazil and the UK, particularly focusing on cultural dimensions and country context that could enlighten our theoretical foundations and hypotheses. 


\subsection{Advergame experience and consumer behaviour}

Since advergames promote interactive content through gaming experiences [15], it is crucial to understand the impact of positive or negative experiences in consumer brand attitudes. Usually, advergames offer an emotional connection between the game, the brand and the consumer [16], which could help to build brand awareness and brand associations [17]. Research indicates that brand familiarity [18,19], product involvement $[15,17,20]$, flow [21,22], arousal [22,23], congruity [17,20,24,25], brand fit [26] and product-game congruity [27-29] influence advergame effectiveness while influencing consumer behaviour. Mostly, advergames can shape consumer behaviour through consumers' perceptions, attitudes and behaviour. For example, the perception of familiarity with a brand inside advergames can determine a consumer's attitudes towards the brand [19]. Taking this into consideration, it is possible to categorise advergame effectiveness in two areas:

1) the actual advergame experience, promoted by the attitudes towards the advergame design; and

2) consumer behaviour, such as attitudes towards the brand and electronic world-ofmouth (eWOM) [30].

In the light of cultural influences in communications for marketing purposes, consumer behaviour can be strongly shaped by cultural values, such as symbols, rituals and heroes [31]. That is, since advergames communicate an advertising message, they should incorporate symbolic communications, (e.g. relevant language and visual aspects), heroes (e.g. ethnicity representations) and rituals (e.g. models of buying products, events, cultural identity by actions). However, to what extent is it possible to incorporate all these elements in advergames? Hernandez et al. [13] found that people from different cultures have different levels of advergame enjoyment based on the way the advergame is designed. Taking this into account, it is crucial to understand the elements could be manipulated in advergames in order to fit one's cultural values and cultural expectations. 


\subsection{Cross-cultural advergames, games and cross-cultural HCI}

The field of Human-Computer Interaction (HCI) has given a lot of attention to cultural issues within this context, which could be represented by several strands such as internationalisation [32], globalisation [33], culturalisation [34] and localisation [35]. What these strands have in common is the concept that while designing interfaces and interactive systems for people from different cultures, it is necessary to adapt aspects of the system in order to suit the user's cultural background. This suggests and supports the idea that the concept of "one-size-fits-all" is not suitable in a global world. Hence, adaptations of content and symbolic meaning within interactive systems should be considered. The difference between these terms is the level of adaptation; culturalisation means different versions for systems, whereas internationalisation is about sharing a common system between cultures [34]. In other words, culture and HCI create different levels of adaptation. Most of the times, these adaptions occur in the representational dimensions, such as colours, icons and symbols; however the challenge is to understand which representations would be changed in order to suit one's culture [34]. Hence, representations still play a big part in the understanding of cultural nuances in interactive systems.

The understanding of one's cultural preferences is a key aspect when dealing with acceptance and trust of interactive systems. For example, Evers and Day [36] proposed that if a system is designed according to people's cultural preferences, it would trigger cognitive, affective and behavioural reactions towards this system, promoting its acceptance and satisfaction. Systems that promote cultural preferences also incorporate symbolic meaning, mediated by cultural values and symbolic associations [37]. Hence, there is a link between a cultural-oriented design and positive experiences.

In cross-cultural HCI, Hofstede's cultural dimensions [6] (e.g. individualism, power distance, uncertainty avoidance, masculinity and long-term orientation) have been intensely employed in order to understand cultural variations in interaction design and user interface design [35]. In the early 2000's, Marcus and Gould [33] identified the influence of Hofstede's dimensions on website interface design. For example, websites from cultures with a high power distance dimension would have more structural features and focus on authority figures, when compared to low power distance cultures. Moreover, 
websites that reflect a familiar cultural background tend to be more trustful [9]. Therefore, the way websites are designed is a reflection of designers' and users' cultural backgrounds and mental models.

Studies in the area of games and culture have looked at variations in game content through culturalisation principles (e.g. game context and assets) [38] and in differences in game mechanics through the lens of Hofstede's dimensions of collectivism-individualism [39]. In that case, Khaled et al. [39] created a game in which the interactions within the game were attached to the individual's cultural background; if collectivist, the non-playing characters (NPCs) would be part of a family and group opinions would emerge from the system in order to persuade players to change their behaviour. This example shows that game interactions are powerful and could be manipulated in order to provide a sense of relevance for the players. In order words, it delivers a sense of familiarity to the player, which evokes positive emotions. However, how would this happen in terms of advergames? Research in advergames has identified that people from different cultures differ in their attitudes towards advergames when presented with the same advergame [13]. This suggested that the design of the advergame, particularly at the level of the integration between the brand and the game, holds an important clue towards the understanding of the influence of those games in consumer behaviour.

Since advergames are advertising, they encompass two sides: one from the game side, including mechanics, interface design and narrative design and another from the advertising side, which incorporates aspects related to the brand. When considering advertising across cultures, it appears that similar design principles exist in cross-cultural HCI research; that is, localisation and adaptation of representative and symbolic elements is central for advertising effectiveness across cultures. One example is the variations across cultures that are high and low context. People from high-context cultures understand and decode information from cues around them and not only from one source of communication $[9,40]$. That is, people from high-context cultures would look for such cues around them and make sense of them. Hence, it is in this scenario that communications across cultures would depend on how people feel familiar with their surroundings and the way the information is presented. In the next section, we argue for a comparison between 
Brazil and the UK, based on cultural dimensions and in particular high-low context aspects of communications.

\subsection{Cultural characteristics of Brazil and the UK}

Differences and similarities between Brazil and the UK are represented by cultural values that reflect psychological influences on persuasion, advergames and consumer behaviour. Brazil, in this case, is a very complex culture. As a combination of several cultures (e.g. European, African and Indigenous) [41], Brazilians value emotions and are highly spiritual and creative people $[42,43]$. Brazilians also understand implicit communications, such as gestures and visual messages, which is a reflection of a high-context culture [44]. According to Hall [44], high-context cultures value less verbal messages and more internal communications based on connections that only members from that culture understand. High-context cultures tend to value tradition and national messages [45]. This suggests that high-context cultures, like Brazil, would prefer messages that have a sense of familiarity and belongingness. Along with that, high-context cultures value visual appeals, when compared to low-context cultures, which tend to prefer textual and objective information [9]. As part of a high-context culture, Brazilians would try to find meaning behind visual messages and possibly understand implicit information incorporated by visual cues.

It is therefore possible to hypothesise that Brazilians and British consumers would have different attitudes towards brands based on their cultural values. The same could be perceived by the way advergames are designed. For example, since Brazilians are part of a high-context culture when compared to the British, Brazilians would prefer advergames that have more visual and graphic images, instead of direct textual information. Thus, a culturally-oriented design would guide cognitive, affective and behavioural reactions towards the advergame, evoking positive experiences after gameplay. In the next section we discuss the main propositions that supported our exploratory study.

\section{Theoretical foundations and hypotheses}

The main premise of this study is to identify a connection between advergame design, advergame experience and consumer behaviour across cultures. As mentioned in the literature review, there is a connection between the way advergames are designed and 
consumer attitudes towards the brand across cultures [13]. In our study, we will focus on the visual representations, particularly because: (1) visual representations are still one of the key elements regarding culturalisation and localisation of content across cultures; (2) research in cross-cultural $\mathrm{HCI}$ has focused on the way content is presented in interactive systems; and (3) high-context cultures tend to value visual information more, if compared to low-context cultures.

The hypothesised model illustrates the relationship between each theoretical foundation that supports the experience. There are five hypotheses that sustain this study. Each of them is categorised in levels: familiarity with the advergame design, advergame experience and consumer behaviour.

\subsection{Hypothesis 1: Level of familiarity}

Understanding culturalisation and the symbolic meaning of objects that could be introduced into an advergame, it is expected that if the advergame is designed to favour a specific culture, it will increase the level of familiarity with those objects and therefore influence consumer behaviour in a positive way. Advergames could evoke a sense of familiarity with the game content. Since high-context cultures value traditional messages, ethnocentric communications and visual representations, it is possible that if advergames promote such aspects, Brazilians would feel more familiar with the advergame itself. However, it is important to state the aspects that could evoke familiarity in the advergame. Since advergames are games that function as a form of advertising, representations of the brand, the game mechanics, storyline and visual appeals (e.g. game scenario, game objects, colour scheme) of the advergame could be key elements in promoting familiarity. Thus, it is possible to assume that:

H1: The level of familiarity with visual representations will be higher for Brazilians than for the British

Considering this, $\mathrm{H} 1$ states that if Brazilians play an advergame designed around their cultural preferences, they would feel more familiar with it, compared to the British. However, giving that visual representations are key aspects for high-context cultures such as the Brazilian culture, we also propose that: 
H1a: Brazilians will feel more familiar with the colour scheme than the British

H1b: Brazilians will feel more familiar with the game scenario than the British

H1c: Brazilians will feel more familiar with the game objects than the British

\subsection{Hypothesis 2 and 3: Level of advergame experience}

An advergame offers an interactive gamified form of advertising. In order words, the "game" part of the advergame is still a game but designed for the purpose of communicating the message about a brand. The level of familiarity could evoke positive experiences, since cultural preferences moderate people's acceptance and satisfaction with interactive systems [36]. Thus, it is expected that since players would feel more familiar with visual representations in the advergame due to their cultural values and background, their level of game experience would be higher. Therefore, we argue:

H2: A higher level of familiarity will lead to a higher level of gaming experience (positive correlation)

Calvillo Gamez, Cairns and Cox [46] have defined game experience through the lens of game enjoyment in a model that determined the Core Elements of Game Experience (CEGE). In other words, game enjoyment stands for a positive experience with the game, evoking positive attitudes towards the game itself. Thus, considering that an advergame will be created in order to favour Brazilians in order to promote possible higher familiarity levels, we argue that:

\section{H3: Brazilians will enjoy the advergame more than the British}

Humour is contextual [47] and since context is a key aspect while dealing with communications across cultures, the addition of humour in order to understand advergame effectiveness and the impact of advergame experience in consumer behaviour is crucial. In fact, familiarity with advertising content could make people laugh and should be incorporated while looking for effectiveness of advertising messages within cultures [47]. Since it is expected that Brazilians would feel more familiar with the advergame, we argue that:

H3a: Brazilians will find the advergame more humorous than the British 
Arousal has a strong relationship with brand attitudes [22,48], influencing the way people perceive brands. Arousal is a state that merges emotion and physiological behaviour [49] and mediates the willingness of people to share content online [50]. In this study, we expect that if Brazilians feel more familiar with the advergame, they would have more positive experiences. Since arousal is an emotional state that emerges from game interaction, it is possible that the way the advergame is designed might also influence arousal. Considering this, we pose that:

H3b: Brazilians will feel more aroused after playing the advergame than the British

\subsection{Hypothesis 4 and 5: Level of advergame effectiveness}

As mentioned in the hypotheses $\mathrm{H} 1, \mathrm{H} 1 \mathrm{a}, \mathrm{H} 1 \mathrm{~b}$ and $\mathrm{H} 1 \mathrm{c}$, if interacting with a familiar advergame interface design, with culturally-favourable visual elements (game scenario, colour scheme and game objects), members from one culture (in this case, the Brazilian culture), would have a more positive game experience. Thus, if considering the influence of visual familiarity in consumer behaviour, we expect that:

H4: A higher level of familiarity will lead to a higher level of advergame effectiveness (positive correlation)

Since advergame experience influences attitudes towards the brand [22], it is also possible to assume that:

H4a: A higher level of gaming experience will lead to a higher level of advergame effectiveness (positive correlation)

Advergame effectiveness means that the advergame has achieved its ultimate goal; that is to influence consumer attitudes and behaviour. There are three factors that define advergame effectiveness: intentions to share the advergame, attitudes towards the brand and the shares of the advergame (behaviour). Since there is the assumption that Brazilians would feel more familiar with the advergame that was designed for them (based on H1), it is expected that this aspect would also influence consumer behaviour. Therefore, the next propositions are:

H5: Brazilians will have more positive attitudes towards the brand than the British after playing the game 
H5a: Brazilians will have more intentions to share the advergame than the British

H5b: Brazilians will share the advergame more than the British

Considering all the propositions, we designed a hypothesised model (see Figure 1), with the aim to address the research question regarding the relationship between advergame design, advergame experience and consumer behaviour.

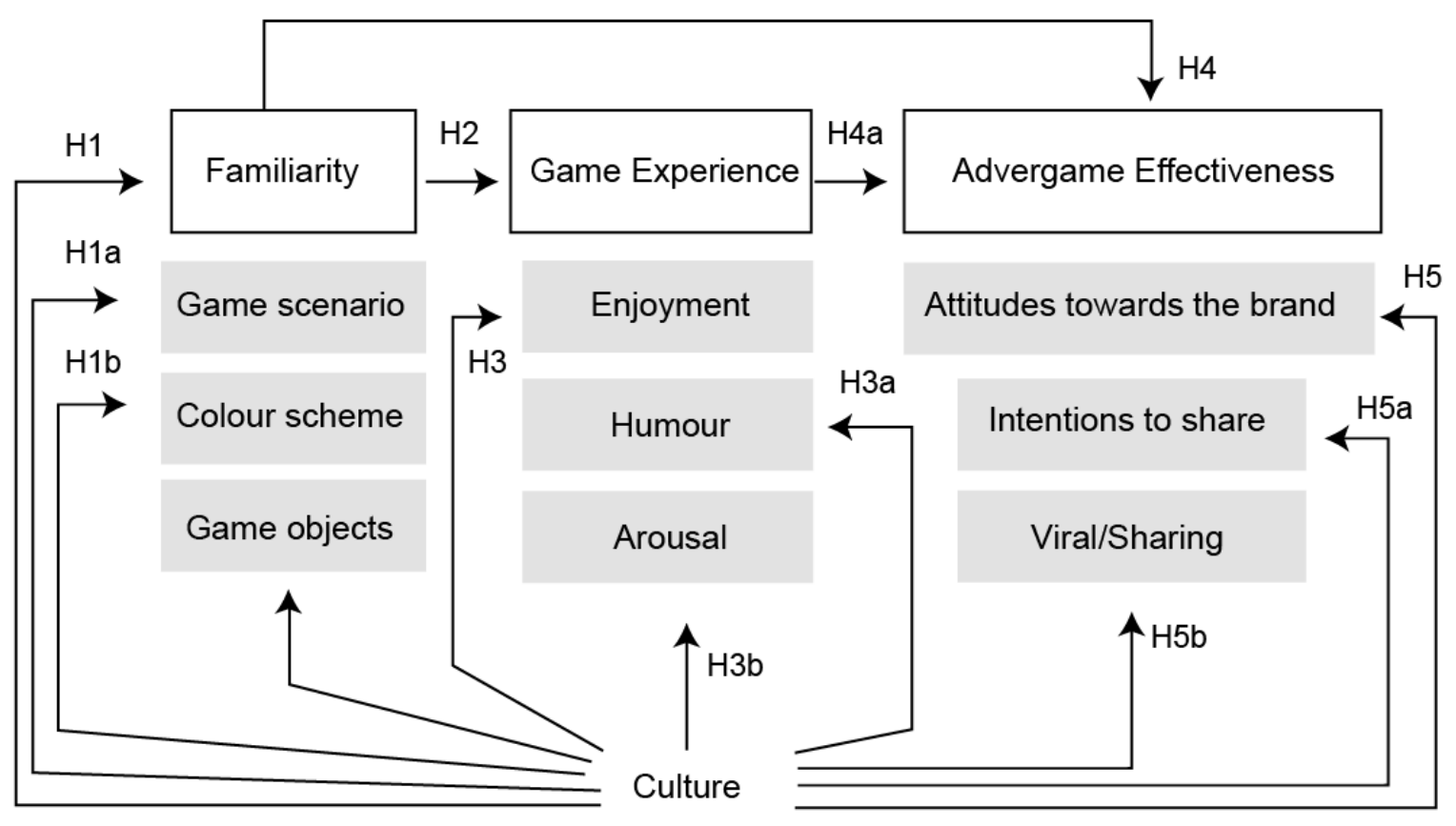

Figure 1 Model of hypothesised relationships

In the next section, we present the methodology employed in order to address and test our research model.

\section{Methodology}

The experiment was designed and tested comparing two groups: Brazilian and British consumers. This is categorised as comparative and hypothesis-testing study, based on experimental game design, through in-game manipulations [51]. The independent variable is culture, whereas the dependent variables are the aspects manipulated in the advergame and consumer attitudes after gameplay. Since it was difficult to manipulate existing games, we had to create our own advergame and target it to one culture. In this case, our designed advergame targeted the Brazilian culture, which functioned as the experimental group in 
our study. Both Brazilians and British played the same advergame; however British played the version in English and Brazilians played the version in Portuguese. Thus, this study puts two different groups at the same condition, which characterises this experiment as a between-group comparison.

The main principle of this study was that while designing the advergame one culture was favoured (in this case the Brazilian culture), Brazilians consumers would feel more familiar with the advergame interface design, which could influence their attitudes towards the brand positively. Taking this into account, we started with the creation of the advergame through particular manipulations in the interface design. These included the adaptation of the colour scheme, scenario and other user interface elements, such as buttons and animations. After the design of the advergame, a questionnaire was developed in order to measure the influence of the elements that were manipulated in the advergame and consumer behaviour. The research model (Figure 1) guided the development of the questionnaire and its sections. Besides the comparison between groups, this study aims to identify correlations between the variables (advergame design, advergame experience and consumer behaviour). Thus, we decided to employ questionnaires in this experiment in order to measure the variables effectively. Questionnaires have been used previously to measure game experience [52]; thus questionnaires are useful tools in this type of study. Since this experiment has defined variables, questionnaires are more suitable for the purpose of this research.

The study was conducted in the following five stages:

1. Advergame design, in which we implemented a semiotic approach in order to provide a confident manipulation of advergame content

2. Questionnaire design, in which the questionnaire was designed, including demographics questions, gameplay and consumer behaviour questions

3. Data collection, in which we shared the link with the questionnaire and advergame with consumers from both countries

4. Correlation analysis, in which the data was analysed with the aim to identify correlations between the manipulations in advergame design, gameplay and consumer behaviour 
5. Differences between group responses, in which the data was analysed with the aim to find differences between the two groups involved in the study (Brazilians/British consumers)

Since our research question looked for the relationship between advergame design, advergame experience and consumer behaviour while comparing Brazil and the UK, the five stages mentioned before were deemed to be suitable as they involve the manipulation

of elements in an advergame and the measurement of the impact of these manipulations in consumer behaviour and advergame experience. In the next subsection, the research design is discussed in detail, starting with the recruitment approach.

\subsection{Participants}

Participants were invited through social media groups (e.g. University student groups, advergame discussion groups, gamification discussion groups) and emails. The age group of the participants was between 18-35 years old, both men and women who were not colour-blind. This specification was described in the invitation email that was sent to the participants. We also added an option to our questionnaire in order frame our sample and make sure that the participant was not colour-blind (e.g. Are you colour-blind?). In this case, any answers with "no" or "I don't know" were discarded. A statement about age limitation and colour-blindness requirement was shared in the invitation, together with a small debrief of the study. The only requirement for the population sample was that participants were Brazilian or British and within the age group of 18-30 years old. To secure that they were from the necessary nationality, a question about participant's demographic information was added to the questionnaire designed for this study.

\subsection{Advergame design and manipulations}

In this section, we explore the design manipulations utilised to develop an advergame. In order to do this, it was necessary to choose a brand to sponsor it. The chosen brand for the advergame design was the Fairtrade Mark for coffee products. Fairtrade has a strong presence in the UK, particularly through the Fairtrade Foundation and in Brazil through the Fairtrade organisation. Also, the choice for this brand could give insights about sustainable consumer behaviour, since the message behind the Fairtrade Mark is the value of optimism, 
respect, action, challenge and integrity, in order to build a fair and straight connection between consumers and producers [53]. Although the current paper did not focus particularly on environmental psychology, the authors identified that there was no advergame sponsored by Fairtrade at the time of the study; thus, with that, the authors could ensure that the advergame was new and, consequently, not played by consumers before. For this particular study, we have chosen the Fairtrade coffee as the main product category. Brazil is the largest coffee producer worldwide [54] and, according to a report from Fairtrade [55], Brazilians consume 1.1 million tonnes of coffee whilst the UK imports $184 \mathrm{k}$ tonnes. Coffee, therefore is a familiar product in both countries, however, Fairtrade is more familiar to consumers in the UK than Brazil. In the UK, most people are familiar with Fairtrade as it is often features on products in supermarkets. The design of the game was semiotically biased towards the Brazilian consumer in order to understand whether certain colours and designs native to Brazilians would evoke familiarity.

\subsubsection{The advergame Colheita de Café}

The advergame Colheita de Café (CC) was designed in order to favour the Brazilian culture. A design approach through semiotics was employed, together with the choice of colour scheme based on previous research [56]. In their study, Madden et al. [56] have identified that Brazilians, when compared to other cultures, prefer the combinations of black and red and white and blue; the most liked colours were white, blue, green, black and red and the least was orange and gold. Colour is an important asset in marketing and it can be shaped by culture. For example, the colour white in means purity in Anglo-Saxon cultures and death in Chinese, Japanese and Korean cultures [57]. Thus, colour is a way to convey meaning through visual cues.

For this study, we have chosen a semiotics approach of design. Semiotics is the study of signs, which function as a representation of something in one's mind [58]. Semiotics applied in design is a concept that allows designers to build meaningful links between people and products [59]. Semiotics can also help to understand the interpretation of persuasive codes that are incorporated by adverts [60]. In fact, in the HCI field, semiotics has been employed in order to give significant context to systems through intuitive interactions and communications [61]. Also, in game design, semiotics has been applied to design game characters, with the aim to represent specific concepts about beliefs [62]. 
Since advergames are advertisements in the form of games and people from different cultures have different ways to perceive symbols and signs [31], there is an opportunity to integrate semiotics with advergame design in a cross-cultural setting.

With the aim of focusing on the Brazilian culture, we searched for the terms that defined the Fairtrade brand for coffee in Brazilian Portuguese (e.g. otimismo, comércio justo, café, cafezinho, etc.) using common and general image banks (e.g. Google Images, Shutterstock, Getty Images, etc.). This helped to obtain a general overview of the main representative elements for Brazilians. Brazilian coffee brand websites were analysed in order to understand the way coffee was presented for Brazilians, with the aim to promote a more general overview of coffee and Fairtrade. In line with a semiotics strategy, the advergame objects and visual design followed the categories of iconic, indicial and symbolic. This means that, for example, a toasted coffee bean could be ass ociated with the colour brown (iconic), with an oval form (indicial) and as a toasted bean (symbolic) (see Table 1). The idea of using semiotics was to make sure that all the symbolic elements were designed within the advergame.

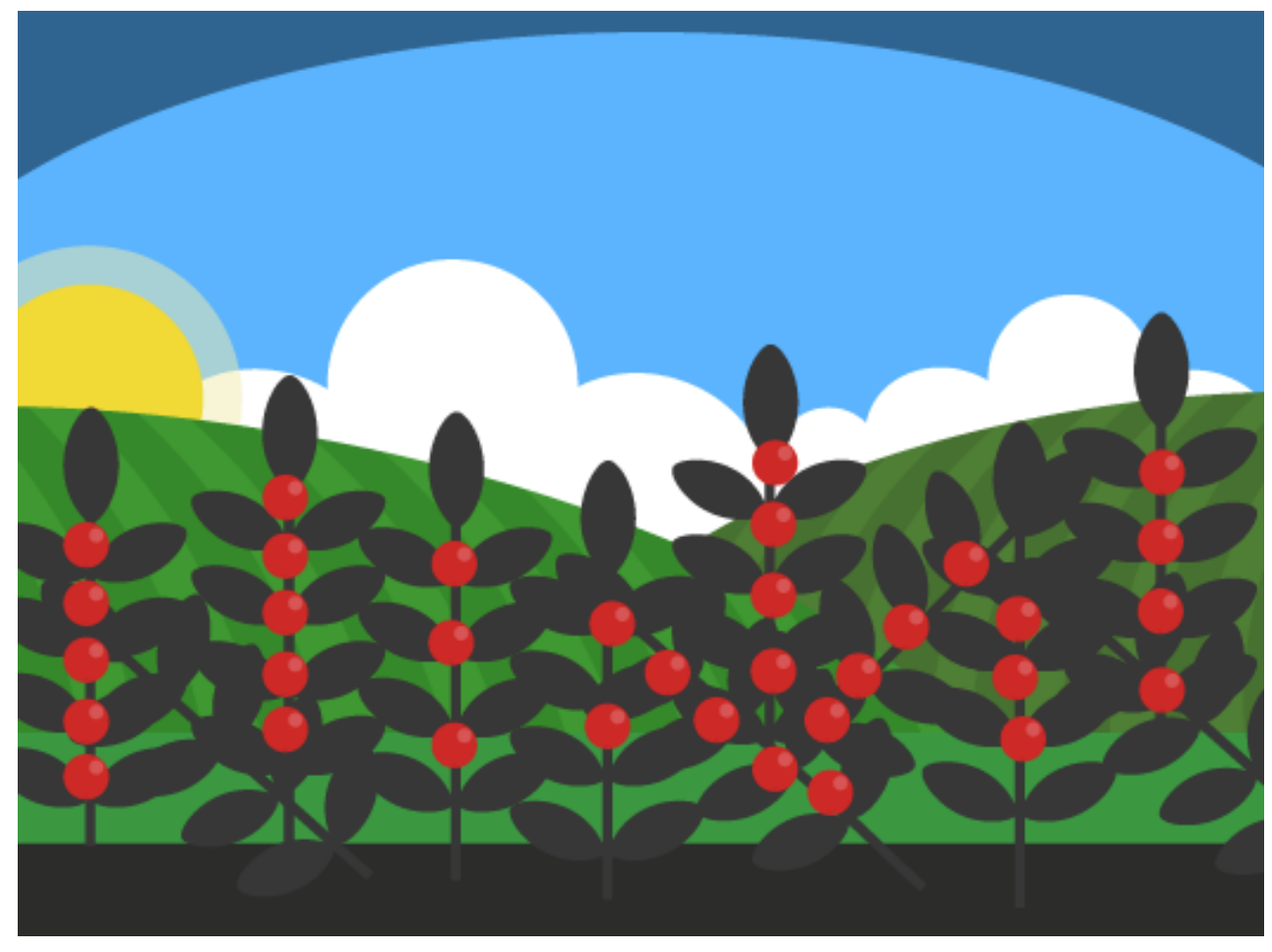

Figure 2 Colour combination of the screen 
In order to design the advergame with a more favourable colour scheme, the combinations proposed by Madden [56] were followed; that is, Brazilians prefer white, blue and green instead of yellow, gold and orange, and a combination of red and black is a favourable one, together with white and blue (see Figure 2). Figure 3 also illustrates the stages of the advergame with each interaction incorporated by the advergame, together with symbols and objects.

Table 1 Semiotic recommendation for the advergame design

\begin{tabular}{|l|l|l|l|}
\hline $\begin{array}{l}\text { Advergame elements } \\
\text { for Fairtrade }\end{array}$ & Iconic & Indicial & Symbolic \\
\hline Coffee (toasted bean) & Colour: brown & $\begin{array}{l}\text { Oval form, smell of } \\
\text { coffee }\end{array}$ & Toasted bean \\
\hline Coffee (cherries) & Colour: red & Circle & Small circle \\
\hline Coffee (drink) & $\begin{array}{l}\text { Colour: brown; } \\
\text { small cup }\end{array}$ & $\begin{array}{l}\text { Smell of coffee, } \\
\text { steam }\end{array}$ & Small cup \\
\hline Environmental & $\begin{array}{l}\text { Green colour. } \\
\text { Sometimes blue. } \\
\text { Trees, oceans }\end{array}$ & Green and blue & $\begin{array}{l}\text { A leaf, tree, hand } \\
\text { holding a tree, } \\
\text { water drop or } \\
\text { recycling symbol }\end{array}$ \\
\hline Economic Outcome & $\begin{array}{l}\text { Yellow, made of } \\
\text { metal for coins }\end{array}$ & Sound of coins & $\begin{array}{l}\text { \$ Symbol, usually a } \\
\text { coin (circle form) }\end{array}$ \\
\hline Social Outcome & $\begin{array}{l}\text { Community, people, } \\
\text { holding hands }\end{array}$ & $\begin{array}{l}\text { People talking, } \\
\text { happy people }\end{array}$ & $\begin{array}{l}\text { Community } \\
\text { symbol: at least } \\
\text { three people } \\
\text { together }\end{array}$ \\
\hline Coffee Farm & Fields, valleys & $\begin{array}{l}\text { Green colour, } \\
\text { country music, } \\
\text { countryside }\end{array}$ & $\begin{array}{l}\text { Green colour, } \\
\text { stripes to } \\
\text { represent the } \\
\text { valleys }\end{array}$ \\
\hline
\end{tabular}



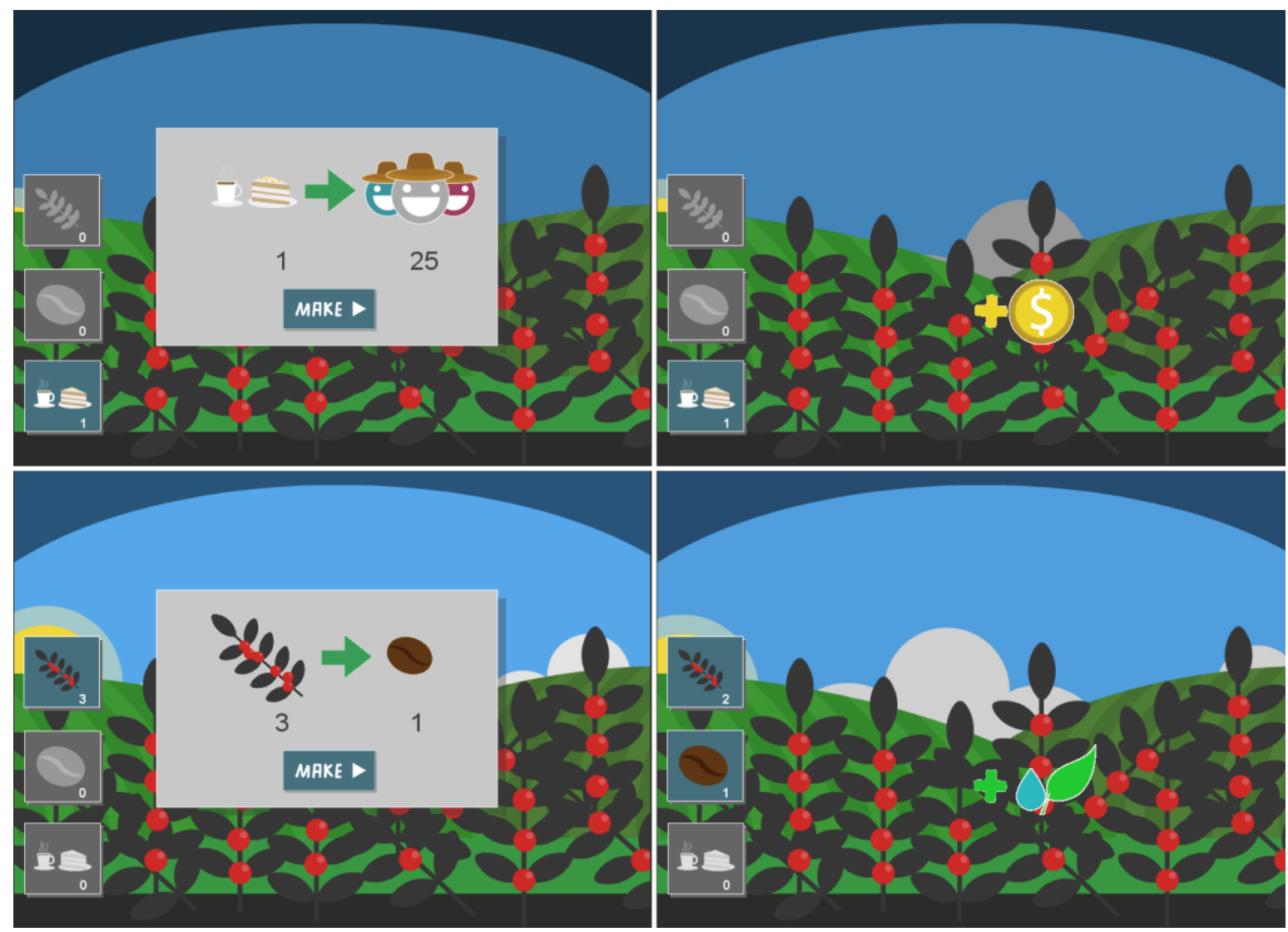

Figure 3 Levels of interaction of the advergame according to each button on the left

The advergame was designed to function online and players could play the game in their computers. We chose this platform due to the simplicity and mechanics of the advergame (e.g. clicking and time-based rules) and the easy access to it. For example, if the advergame was mobile, it could be difficult to ensure that everyone would have the same experience since mobile phones could have different systems, sizes, etc. Also, it was not the objective of this study to understand the impact of the advergame platform in consumer behaviour. Thus, the authors chose a simple approach for the design the advergame.

In the next stage, the process adopted to evaluate the relationship between advergame design, advergame experience and consumer behaviour using a questionnaire is described.

\subsection{Questionnaire development}

The aim of the questionnaire was to measure the relationship between familiarity with elements of the advergame, the advergame experience and cross-cultural consumer 
behaviour. This relationship is represented in the hypothesised model (see Figure 1). The questionnaire was separated in six sections:

1. Demographic questions. These were related to: level of education, country, state and colour-blindness. The addition of demographic questions was important in order to assure that the sample was correctly selected for the purpose of this study. In the same section of demographic information, a section about previous gameplay experience was added. For the question about previous gameplay experience, a the 7-point Likert-type scale (1=never, 7=daily) from Besharat et al. [29] was adopted, with one question about "how often" players play games. The following sections of the questionnaire were also composed of 7-point Likert-type scales.

2. Attitudes towards the brand before gameplay. A question about attitudes towards the brand was added based on previous scale that was already proven statistically significant (Cronbach's $\alpha=0.93$ ) [63]. The addition of a question about attitudes towards the brand before the gameplay was crucial in order to promote a comparison between attitudes before and after, with the aim to analyse the effectiveness of the advergame.

3. Advergame experience. A question about arousal was added to the questionnaire, using the 7-point scale developed by Berger [50] (Cronbach's $\alpha=0.85$ ). A question about humour was also added, based on the 7-point scale developed by Chattopadhyay and Basu [64], when looking for the presence of humour in advertising. Furthermore, the scale for enjoyment was added, based on Calvillo Gamez et al. [46] Core Elements of Game Experience Questionnaire (CEGEQ). For the purpose of this study, we included the elements about the player's perception of the game, such as game environment and gameplay characteristics; these two factors determine game enjoyment.

4. Advergame effectiveness. A question about intentions to share the advergame was added to the questionnaire. For that, we used Berger's [50] scale (Cronbach's $\alpha=$ 0.74) of intentions to share online content with friends and family. At the end of the advergame, players could also share their score in Social Media. Clicks on this button were computed. The same question for attitudes towards the brand was added at the end of the questionnaire. 


\section{Open-ended question about overall gameplay experience. An open-ended}

question was added to the questionnaire, in order to address any specific elements that could emerge from the advergame experience and consumer behaviour that players may wish to comment or suggest.

6. Advergame familiarity. In order to measure the familiarity with advergame design, it was necessary to design a scale that could measure how familiar players would be with elements from the advergame. 8 items were added to this 7-point Likert-type scale. The details of the scale are discussed in the next subsection.

The use of above factors and research design meant that the questionnaire had 30 questions after gameplay and 8 questions before gameplay, which created total of 38 questions, including the open-ended question at the end of the questionnaire. In the next section the scales to measure the relationship between advergame design, advergame experience and consumer behaviour, while comparing Brazil and the UK are discussed.

\subsubsection{Measuring familiarity}

The main premise behind familiarity in this study is that if Brazilians interact with a familiar advergame, their attitudes towards the game and the brand would be more favourable. Since there was no scale that could measure familiar aspects from the advergame, it was necessary to create an instrument to measure this relationship. Considering the main aspects discussed in the literature review, the main components of the advergame design are: advergame theme, such as the context and the content of the advergame (e.g. in the CC advergame, the theme is about helping coffee farmers to pick their coffee beans on time, following each stage of coffee production, until selling, bringing the awareness of the Fairtrade coffee that is composed of several stages), the advergame narrative, the representations of the brand inside the advergame (related to brand congruity and integration between the brand and the game), the advergame environment, such as sound, music, visual elements, buttons, scenario, game objects and avatars (if existing in the advergame) and the advergame rules (e.g. rules and mechanics, reflected by the game genre). In order to measure the familiarity with the advergame design considering all the aspects of design, 8 items were added (see Appendix A for the whole scale). 


\subsubsection{Measuring advergame experience}

Advergame experience is a combination of enjoyment, arousal and humour. Game enjoyment is a positive experience that players have while playing games and could be conveyed by two elements: the sense of control over the game and the player's perception towards the game design [46]. Since this study looks for the relationship between visual advergame design elements, it is necessary to measure player's perceptions towards these elements in the advergame design. Thus, the scales that represent game environment and gameplay were more appropriate to this research (see Appendix A).

\subsubsection{Measuring advergame effectiveness}

Advergame effectiveness is measured by consumer behaviour, which includes consumer attitudes towards the brand, intentions to share the advergame and actual shares of the advergame. Attitudes towards the brand has been the most utilised measurement of the impact of advergames in consumer behaviour, particularly when considering game enjoyment [24]. Thus, for this study, we measured advergame effectiveness through attitudes toward the brand. Another aspect that influences advergame effectiveness is the intention to share the advergame. Intentions to share the advergame are strongly related to electronic world-of-mouth (eWOM) [30]. That is, since intentions precede actions in consumer behaviour [65], intentions are as important as actual shares, when measuring advergame effectiveness. Furthermore, sharing the advergame is one indicator that consumers are emotionally involved with the advergame content [66]. Considering this, we used Muehling and Laczniak's [63] brand attitudes scale to measure attitudes, together with Berger's [50] scale of intentions to share the content online and the clicks on the social media button as an indicator of actual behaviour.

\subsection{Procedure}

The advergame was implemented online ${ }^{1}$. Participants from both countries could play the advergame for one minute; the advergame was designed to last one minute, since it was a one-level game (see section 4.2.1 for design choices). The link for the research was shared

\footnotetext{
${ }^{1}$ Play the British advergame online at: http://do-doc-ahedron.co.uk/research/uk/onossocafezinho/ and http://do-doc-ahedron.co.uk/research/uk/onossocafezinho/ for the Brazilian version
} 
in Facebook pages and groups. For that, we have used a snowballing and random sampling strategy as participants could invite other participants to take part in the study. The application of the questionnaire was separated in three phases (see Table 2):

1. Before gameplay, in which participants answered demographics questions, including their previous gameplay experience and questions about the brand. Participants were informed about the ethics of the study beforehand.

2. Gameplay, in which participants were invited to play the advergame online with a limited time of one minute. This constraint was already limited by the advergame design; the advergame had a time limit for the players to finish their task. Participants were introduced to the rules of the game in the same link. After reading the instructions, participants could press a "start" button and begin the game.

3. After gameplay, in which participants answered questions about their gameplay experience, questions about the brand and willingness to share the advergame. At this stage, clicks in the share button from the game were also computed.

The process was piloted with 2 participants before sending the invitations to all potential participants (1 British player and 1 Brazilian player). The whole procedure took around 20 minutes. The advergame itself had a limited time for gameplay, which made the experience manageable for the researchers. In order to control the context of play, in the questionnaire form participants were advised to play the advergame in a web browser and computer screen, avoiding phones and tablets.

Table 2 Summary of measurements for each stage of the study and questionnaire

\begin{tabular}{|l|l|l|}
\hline Before gameplay & Gameplay & After gameplay \\
\hline Demographic questions & $\begin{array}{l}\text { Game enjoyment } \\
\text { (environment and } \\
\text { gameplay) [46] }\end{array}$ & Intentions to share [50] \\
\hline $\begin{array}{l}\text { Attitudes towards the brand } \\
{[63]}\end{array}$ & Arousal [50] & $\begin{array}{l}\text { Attitudes towards the brand } \\
{[63]}\end{array}$ \\
\hline
\end{tabular}




\begin{tabular}{|l|l|l|}
\hline $\begin{array}{l}\text { Previous gameplay } \\
\text { experience [29] }\end{array}$ & Humour [64] & \\
& & \\
\hline
\end{tabular}

\section{Data analysis and results}

In total, 64 people participated in the experiment $(n=64) .73 .4 \%$ were undergraduates, 65.6\% from 18-25 years old, 45.3\% male and 53.1\% female. From the 64 participants, 34 (n1=34; 6.3\% from Hampshire and 6.3\% from Surrey) were from the UK and 30 were Brazilians (n2=30; 39.1\% were from Rio de Janeiro). The 38-item questionnaire (excluding the six items for demographic data and the open question) was proven statically reliable (Cronbach's $\alpha=0.873$ ). The scales were also tested separately: familiarity with eight items scored $\alpha=0.871$ and with three items (colour scheme, game objects and game scenario), $\alpha$ $=0.936$. The scale for advergame effectiveness (attitudes towards the brand and virality) scored $\alpha=0.849$. This shows that all scales were statistically reliable.

When testing for reliability, the scale of game enjoyment, composed of environment and gameplay with 14 items, borrowed from Calvillo Gamez et al. [46] scored $\alpha=0.682$, which could be improved if the item "I did not like the scenario" was deleted (improved from $\alpha=$ 0.682 to $\alpha=0.757)$. Thus, for the analysis of game enjoyment, this item was deleted and only 13 items computed the variable game enjoyment. If considering the scale that measure humour [64], the $\alpha$ was negative, but with the deletion of 2 items ("dull" and "boring"), the humour scale scored $\alpha=0.918$. Therefore, the final scale had 35 questions (instead of 38), with $\alpha=0.916$ (see Appendix A).

In order to compare the means between Brazilians and British, we employed a MannWhitney (MW) test and Wilcoxon's rank-sum test. This was necessary as our data was not normal. We divided the results into four levels: level of familiarity (H1, H1a, H1b), level of advergame experience ( $\mathrm{H} 2, \mathrm{H} 2 \mathrm{a}, \mathrm{H} 2 \mathrm{~b})$, level of advergame effectiveness and other possible effects that emerged from our results (H4, a, H5, H5a, H5b). This approach was undertaken in order to address our hypotheses and explore the relationships between variables. The level of statistical significance taken in this study was $\mathrm{p}<0.05$. 


\subsection{Level of familiarity}

When testing for variations in terms of familiarity between Brazilians and British $(\mathrm{p}=0.015$, $\mathrm{Z}=-2.230, \mathrm{r}=-0.27)$, game theme, brand familiarity, game graphics, game scenario and game colour scheme were statistically significant. On the other hand, music, rules and narrative did not vary significantly. This suggests that Brazilians felt more familiar with the aspects that were manipulated in the advergame (scenario, colours and graphics) $(M=5.2, S D=1.69)$ than the British did ( $M=4.25, \mathrm{SD}=1.59)$. This supports $\mathrm{H} 1$, if considering only the 3 items manipulated in the advergame (scenario, colours and graphics), which shows that Brazilians felt more familiar with the visual aspects of the advergame. This also supports H1a, H1b and H1c. Since only the 3 aspects were strategically manipulated in the advergame, for the purpose of the understanding of the relationship between advergame design, advergame experience and consumer behaviour, we considered the variable familiarity in this study as a combination of these 3 factors. Thus, for the correlation analysis between familiarity, advergame experience and advergame effectiveness (or consumer behaviour), only the 3 items were computed in order to measure familiarity.

When looking for the items from the variable familiarity separately, it was possible to see that the effect of game objects and graphics was stronger $(\mathrm{p}=0.006, \mathrm{Z}=-2.768, \mathrm{r}=-0.346)$ than game scenario $(\mathrm{p}=0.013, \mathrm{Z}=-2.483, \mathrm{r}=-0.310)$ and colour scheme $(\mathrm{p}=0.046, \mathrm{Z}=-1.998$, r=-.024). This supports H1a, H1b and H1c. Figure 4 summarises the results according to each hypothesis that supported this study. 


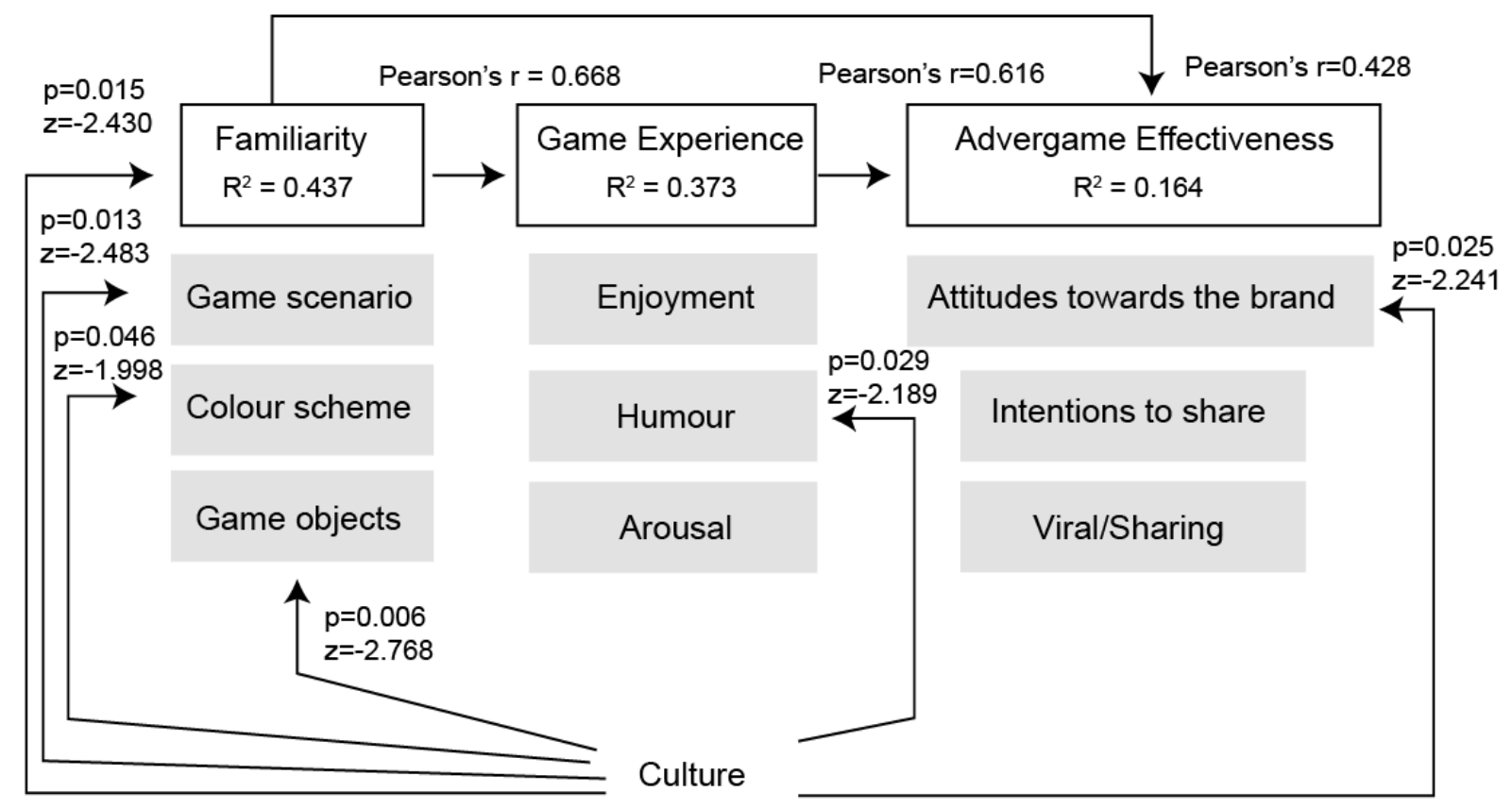

Figure 4 Research model and the results

\subsection{Level of advergame experience}

When testing for correlations (related to $\mathrm{H} 2$ ), it was possible to notice a statistically significant variance and positive correlation $(r=0.668)$ between familiarity $(M=4.58$, $\mathrm{SD}=1.59)$ and advergame experience $(\mathrm{M}=4.15, \mathrm{SD}=0.89)$. The coefficient of determination was R2 $=0.437$, which shows a medium effect (see Figure 5). This showed that higher levels of familiarity (with game theme, game graphics, colour and scenario) promote higher levels of advergame experience, reinforcing the arguments from $\mathrm{H} 2$. 


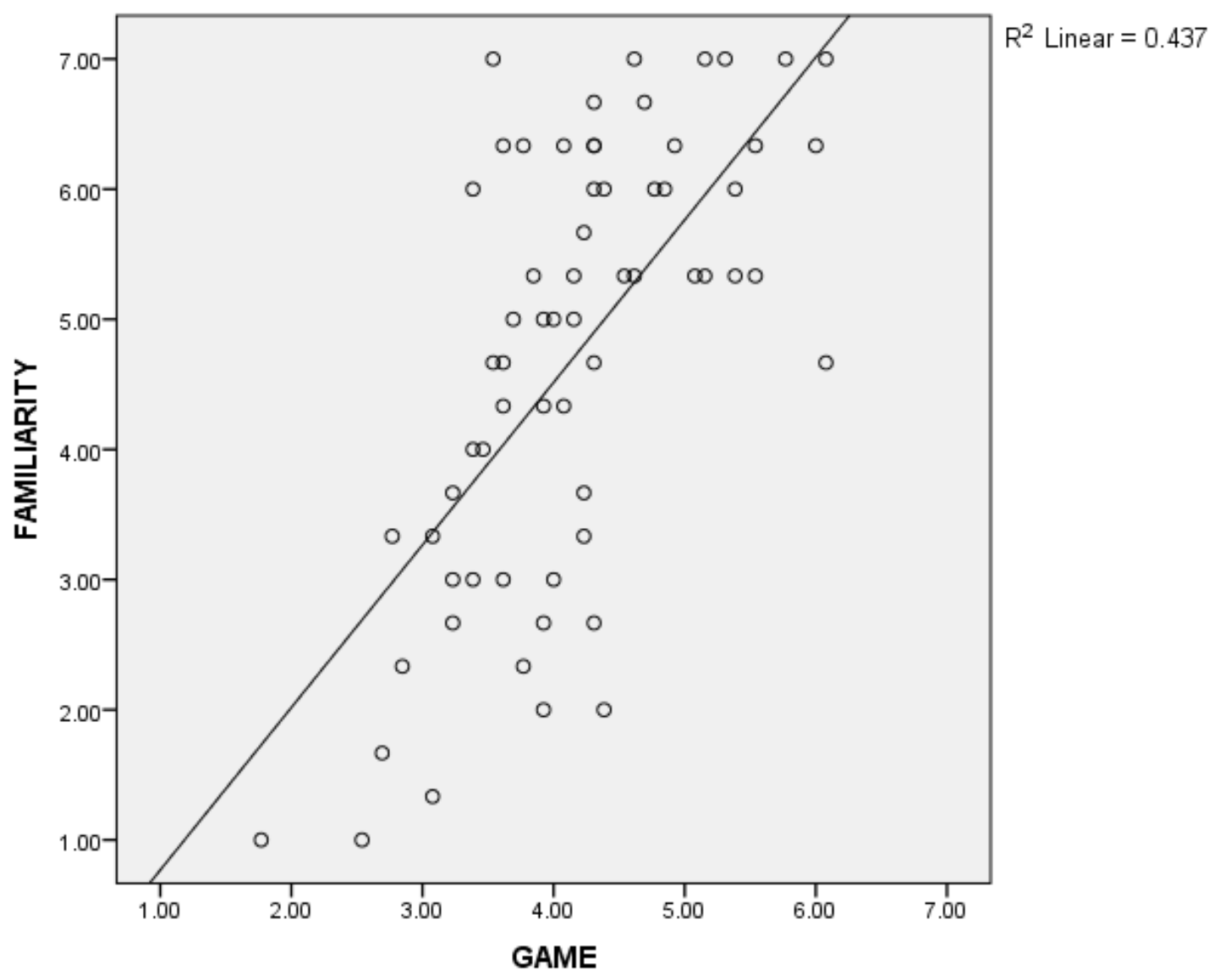

Figure 5 Correlation between Familiarity and Advergame Experience $(\mathrm{R} 2=0.437)$ On the other hand, the difference between Brazilian and British responses in terms of advergame experience was not statistically significant; therefore, it is possible to say that both Brazilians and British players had the same advergame experience. This rejects $\mathrm{H} 3$, $\mathrm{H} 3 \mathrm{a}$ and H3b (see Figure 4). Considering this, the results suggest that although familiarity could influence advergame experience due to its correlation coefficient level, the advergame experience itself did not vary for British and Brazilians. They both had the same attitudes towards the advergame. Moreover, no statistically significant variance was found for arousal levels, which also shows that Brazilians and British players had the same level of advergame experience. If considering humour, Brazilians found the game funnier than British ( $p=0.029, \mathrm{Z}=-2.189, \mathrm{r}=-0.277)$; however, the effect was too small $(\mathrm{r}<0.3)$. This supports H3a. 


\subsection{Level of advergame effectiveness}

With the aim to address the hypotheses $\mathrm{H} 4$ and $\mathrm{H} 4 \mathrm{a}$, we employed a correlation analysis for both variables (familiarity and game experience). It was possible to observe a positive and significant correlation between familiarity $(\mathrm{r}=0.428, \mathrm{R} 2=0.164)$ and advergame effectiveness and a positive and significant correlation between game experience and advergame effectiveness $(\mathrm{r}=0.616, \mathrm{R} 2=0.373)$. This supports both $\mathrm{H} 4$ and $\mathrm{H} 4 \mathrm{a}$. However, if looking for differences in the level of prediction of advergame effectiveness considering both familiarity and game experience, the latter has a stronger impact than the former (see Table 3 for multiple regression and Figure 6).
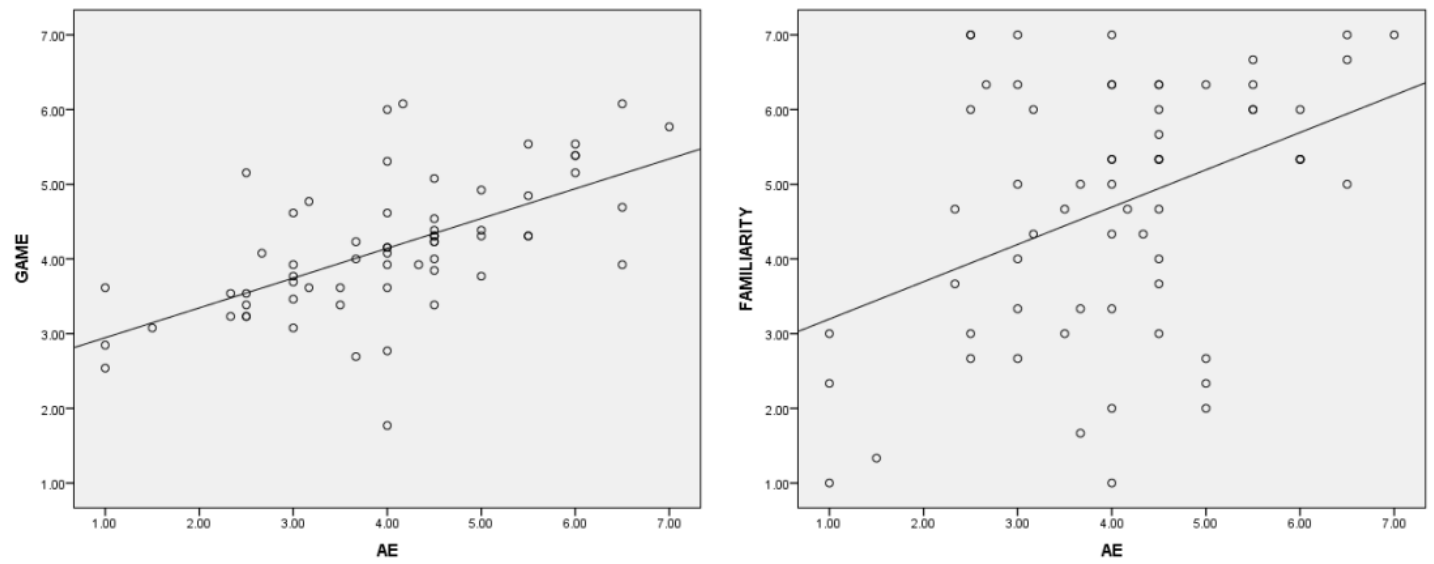

Figure 6 Plot illustrating the correlation between advergame experience and advergame effectiveness (left) $(\mathrm{R} 2=0.373)$ and familiarity and advergame effectiveness (right) $(\mathrm{R} 2=$ 0.164)

Table 3 Multiple regression

\begin{tabular}{|c|c|c|c|c|c|c|}
\hline \multicolumn{7}{|c|}{ Coefficients $^{a}$} \\
\hline \multirow{2}{*}{\multicolumn{2}{|c|}{ Model }} & \multicolumn{2}{|c|}{$\begin{array}{l}\text { Unstandardized } \\
\text { Coefficients }\end{array}$} & \multirow{2}{*}{ 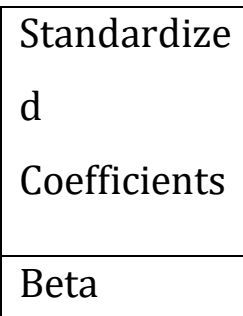 } & \multirow[t]{2}{*}{$\mathrm{t}$} & \multirow[t]{2}{*}{ Sig. } \\
\hline & & B & Std. Error & & & \\
\hline \multirow[t]{2}{*}{1} & (Constant) & .135 & .661 & & .204 & .839 \\
\hline & FAMILIARITY & .002 & .109 & .002 & .014 & .989 \\
\hline
\end{tabular}




\begin{tabular}{|l|l|l|l|l|l|l|}
\hline & GAME & .934 & .207 & .610 & 4.516 & .000 \\
\hline
\end{tabular}

In this study, advergame effectiveness is being measured by attitudes towards the brand and the intentions to share the advergame. As mentioned previously, it was necessary to measure the means from attitudes before the advergame and after the advergame. In both scenarios, it was possible to see a significant difference between Brazilians/British attitudes before $(\mathrm{p}=0.025)$ and after $(\mathrm{p}=0.016)$ playing the advergame, with British with more favourable attitudes towards the brand than Brazilians in the two scenarios (before gameplay and after gameplay). Thus, this rejects H5. However, it is possible to notice a difference from the means from before gameplay and after gameplay in both samples (see Table 4). In this case, Brazilians increased their attitudes towards the brand after gameplay, whereas British decreased their attitudes towards the brand also after gameplay.

The actual shares of the advergame (clicks on the button), they were very low. Only five Brazilians clicked on the button, whereas eight British shared the advergame. This aspect rejects H5b, since it was expected that Brazilians would share more the advergame than British. There was also no significant difference between Brazilian and British intentions to share the advergame, which rejects $\mathrm{H} 5 \mathrm{a}$.

When analysing for the open-ended questions, only six people answered this question with short sentences or words. Since the number of answers was small and composed of short sentences, the researchers could not add them to the analysis. Yet, it was possible to identify a significant variation between the samples in terms of previous gameplay experience; Brazilians had a mean of 3.30, when compared to British, with 5.21 and this difference was statistically significant. When looking for a possible correlation of previous gameplay experience with familiarity, game experience and advergame effectiveness, no statistical significant relationship was found. This shows that cultural effects were more important for this study.

Another aspect to mention was brand familiarity. When comparing Brazilian and British levels of brand familiarity, British showed a higher level of brand familiarity $(M=5.12)$ if 
compared to Brazilians ( $\mathrm{M}=2.73)$. If looking for correlations between brand familiarity and advergame effectiveness alone, it was possible to notice a positive correlation ( $\mathrm{r}=0.483)$. Although there was no hypothesis in this study related to this fact, this could help to enlighten our discussion about the results, which debated in the next section.

Table 4 Attitudes towards the brand before and after playing the game

\begin{tabular}{|c|c|c|c|}
\hline \multicolumn{2}{|c|}{ Country } & ATTITUDES (before) & ATTITUDES (after) \\
\hline \multirow[t]{3}{*}{ UK } & Mean & 5.9020 & 5.7745 \\
\hline & $\mathrm{N}$ & 34 & 34 \\
\hline & Std. Deviation & 1.15624 & 1.49684 \\
\hline \multirow[t]{3}{*}{ Brazil } & Mean & 4.9333 & 4.9667 \\
\hline & $\mathrm{N}$ & 30 & 30 \\
\hline & \begin{tabular}{|l|} 
Std. Deviation \\
\end{tabular} & 1.70732 & 1.63381 \\
\hline \multirow[t]{3}{*}{ Total } & Mean & 5.4479 & 5.3958 \\
\hline & $\mathrm{N}$ & 64 & 64 \\
\hline & Std. Deviation & 1.50978 & 1.60233 \\
\hline
\end{tabular}

\section{Discussion}

This study explored the influence of visual familiarity in advergame effectiveness across cultures, analysing three levels: familiarity, advergame experience and advergame effectiveness. For that, we developed an advergame favouring Brazilian cultural preferences through a semiotics design approach and we compared the responses between Brazilians and British consumers. Our findings (see Appendix B for more details) show theoretical and managerial contributions to the field, such as the impact of visual familiarity in advergame effectiveness and implications for both Brazilian and British markets.

\section{Theoretical and managerial contributions}


The main premise of this study was that if Brazilians were familiar with the visual advergame interface elements, they would have a more positive advergame experience and favourable attitudes towards the brand. The results showed that compared to British consumers, Brazilians felt more familiar with visual aspects within the game, composed of game scenario, colour scheme and game graphics and objects. This supports the premises of cross-cultural HCI, which includes the concepts of localisation [33,35] and culturalisation $[38,67]$ (i.e. the adaptation of interface elements according to cultural preferences). It also reinforced the idea that visual aspects play a strong part when studying advergames across cultures. This paper also presented an application of semiotics in advergame design, which was not undertaken before.

Another contribution of this exploratory study was the symbolic association that consumers had with elements within the advergame. Since the advergame was designed around symbols and objects in order to favour Brazilians, this study also supports the idea that symbolic associations influence consumer behaviour [37]. Within that, it also showed that semiotics could be a useful tool to evoke familiar associations in advergame design across cultures. Although our study showed only one application of semiotics in advergame design, practitioners could consider implementing this design strategy when they design advergames for different cultures and markets. In addition, further research analysing the influence of semiotics in advergame design could be undertaken in order to develop a semiotics model of advergame design that could be applicable to different cultures.

Our findings also indicated that before and after playing the advergame, Brazilian and British consumers varied in their attitudes towards the brand. However, it is important to mention that British consumers had more favourable attitudes towards the brand than Brazilians in both stages. We found differences in their attitudes before and after gameplay as the British were less favourable towards the brand after playing the advergame, whereas Brazilians were more favourable towards it. Therefore, we concluded that since the Brazilians were familiar with visual elements of the advergame, this made them more favourable towards the brand, whereas the British, who were not familiar with the visual elements were less favourable towards the brand. Our study, therefore, supported Waiguny et al.'s [19] arguments regarding the influence of the content of the advergame (e.g. theme, story, mechanics, assets) influencing attitudes towards the brand. It is therefore possible 
that in our experiment, Brazilians could have felt a positive connection with the advergame content as it was familiar for them, helping them develop a more favourable attitude towards the Fairtrade brand. As a result of this study, when designing advergames for consumers across the globe, marketers and developers should try to localise the game scenario, colour scheme and game objects, in order to be more effective and relevant for different sets of consumers.

This study also brought insights about the influence of brand familiarity in advergame effectiveness across cultures. Brand familiarity moderates implicit attitudes towards the brand [19]. Since British consumers were more familiar with the brand, they could have had already an emotional attachment with the brand that was not completely influenced by the advergame design. Thus, it is possible that if the advergame was designed around an unfamiliar brand, the results could have been different since consumers would not have a pre-conception about the brand. For example, it is possible that if the advergame was designed around an unfamiliar brand we would have noticed a stronger influence of visual familiarity in advergame effectiveness, since the association with advergame content sponsored by unfamiliar brands tends to be more robust if compared to familiar brands [19]. Further studies that could compare advergames sponsored by familiar and unfamiliar brands could be extremely valuable for the field of advergame design across cultures. It is also possible that there were political and social implications towards Fairtrade and coffee. Since Brazil has a role of producer and the UK as importer of coffee, there is a possibility that other influences such as historical relationships between both countries (and the role that coffee has in each country) could have impacted the way consumers perceive the brand. This aspect could be addressed in future research and could help to give better insights for marketers and advertisers in terms of policy making and trading.

\section{Implications for Brazil and the UK}

Brazilians were less familiar with the brand but were more familiar with the advergame visual elements (game scenario, colour scheme and game objects). This helps to confirm that Brazilians value contextual cues, in order to decode messages. It also supports Hall's [44] dimensions that Brazil functions as a high-context culture and Hermeking's [9] propositions that high-context cultures value visual communications. Thus, studies that compare high-low context cultures could benefit from this research. On the other hand, 
when Hofstede's dimensions were looked at [6], no differences were found. This suggests that looking at only Hofstede's cultural dimensions might not be enough to understand cultural differences when analysing advergames across cultures.

Brazilians were also familiar with the colour scheme, which supports Madden et al.'s [56] study. According to Madden et al. [56], Brazilians prefer a combination of red and black and the colours white, blue and green. Although their study was undertaken in early 2000s, it was still supported in our experiment. It is, nonetheless, possible that the Brazilian level of familiarity with the colours was also enhanced by the design of the advergame, which featured a sky, a coffee farm and fields that are usually represented by the colours blue and green. Thus, further studies could investigate the impact of other colour schemes in different types of scenarios in advergames across cultures.

Both Brazilians and British had the same advergame experience. Thus, although Brazilians were more familiar with visual elements in the advergame, they had the same level of experience in terms of enjoyment and arousal. However, Brazilians found the advergame more humorous than British; this indicates that Brazilians operate in a high-contextual cultural dimension, supporting Hall's dimensions [44], since humour is moderated by culture [34] and it is contextual [47].

British were more familiar with the Fairtrade brand when compared to Brazilians. This difference could be a significant finding for studies between Brazilians and British, since it was expected that they would have similar levels of familiarity. It is possible that the British market has more accessibility to Fairtrade products and because of that, they might have a higher brand awareness. In a report published in 2006, the coffee Fairtrade market has risen from 14 to $20 \%$ in 4 years in the UK [68]. The UK is the largest international market of Fairtrade general products [69]. In fact, British consumers who respect green values are keener to buy Fairtrade products [70]. Fairtrade marketers could use these findings to work towards higher brand awareness in Brazil. Also, although the current study did not aim to research environmental psychology across cultures, it is possible that future research in the area could be developed.

\section{Limitations and further research}


One limitation could be the type of advergame designed for this research. It is possible that since the advergame had a limited time of one-minute gameplay, players did not feel sufficiently immersed in the advergame. Although the current experiment did not measure immersion, it is possible that if the advergame was 5-10 minutes long it could have promoted an immersive experience. For example, according to Jennett et al. [71], 5-10 minutes should be enough for players to feel immersed within a game. Thus, in the future, research that could measure immersion of advergames across cultures could be extremely useful for insights about advergame design.

Another aspect to consider is the sense of control that players had while playing the advergame. This study has utilised the CEGE scale [46] of game environment and gameplay in order to measure game enjoyment. However, the CEGE scale had other two factors that were not used in this study: control and puppetry. Those factors are also determinants of game enjoyment, together with game environment and gameplay. Thus, it is possible that a further study including the whole CEGE scale could have been valuable in order to measure the influence of game control in advergame experience. Since the advergame had a single type of interaction (clicking), it is possible that advergames with different mechanics could have a different impact in the sense of control and therefore in game enjoyment.

Although this study did not investigate the effect of different game mechanics, consequences, levels and rewards in advergame experience and advergame experience across cultures, it is possible that players could have had different advergame experiences if the advergame had localised rewards or consequences. For example, Khaled et al. [72] have employed different consequences, rewards and feedback systems for collectivist and individualist cultures when designing persuasive games for health. Considering this, further studies could be undertaken in order to address different rewarding systems in advergames across cultures.

Another limitation was the brand chosen to sponsor our advergame (Fairtrade). Since British and Brazilians had different levels of brand familiarity, this could have influenced our study. Although this difference was considerable, it did not impact the effect of visual familiarity. However, further studies could consider familiar vs. unfamiliar brands (e.g. fictitious brands), other types of brand category (e.g. high involvement brands vs. low involvement) and aspects like country-of-origin (COO). For example, a positive COO could 
have a positive influence in attitudes towards the brand [73]. Thus, studies that investigate those aspects in advergames across cultures could be extremely valuable to the field of interactive marketing and games design across cultures.

We also acknowledge that the sample size utilised in our experiment might not be enough to make general claims about Brazilian and British population as a whole. Still, our experiment showed significant differences between the two populations. However, in the future, more research could be undertaken with a larger sample, also considering differences between regions in Brazil and in the UK (e.g. south-north). Although our experiment had some limitations, due to its exploratory nature, this paper could be a starting point for researchers who want to investigate the influence of advergame design elements in consumer behaviour across cultures.

\section{Conclusion}

This paper argued that familiarity with visual aspects in advergames, conveyed by a semiotics approach, could influence advergame effectiveness, if considering attitudes towards the brand and the intentions to share the advergame, when comparing the responses of Brazilian and British respondents. During the study, participants played the same advergame, which was designed in order to incorporate visual elements (game scenario, game objects and colour scheme) that could favour the Brazilian culture. The advergame created for this study (Colheita de Café) featured the Fairtrade Mark for coffee and was designed to favour Brazilian cultural preferences. For that we utilised a semiotics approach of advergame design, which integrated iconic, indicial and symbolic elements within the advergame.

The results showed that visual familiarity with elements in the advergame could influence consumer behaviour across cultures. Brazilians felt more familiar with the visual elements that were semiotically integrated in the advergame and this impacted on their attitudes towards the brand. On the other hand, British did not feel familiar with the visual elements and had less favourable attitudes towards the brand. This also showed that Brazilians probably operate according to Hall's [44] cultural dimensions of high-context in communications, which can be a significant finding for studies that investigate the influence of advergame design across Latin American countries. In addition, our study 
could be valuable for marketers and developers who design advergames for brands across the globe. Since Brazilians could spot familiar elements within advergame design, marketers and developers could create a single version of the advergame with differences in game scenario, colour scheme and game objects, without having to change the advergame mechanics. For example, an advergame originally created in English could have the same version in Brazil but with differences in game scenario, colour and objects. Yet, since Brazilians were more familiar with the visual elements in the advergame than British, our study also showed that semiotics could be a useful approach for cross-cultural design research.

In terms of moving forward, it would be useful to incorporate avatars or NPCs, which could help to increase the feeling of immersion in the advergame providing more of a sense of control in the game. This would help in understanding how familiarity with culturally-led design elements help immersion and gameplay.

Also, more studies about Fairtrade consumption, political and economic issues and sustainable consumer behaviour values could be undertaken. The premise of Fairtrade is based on sustainability, especially for farmers in terms their livelihoods and in managing the resources with less pollution [74]. Thus, research that investigates the influence of sustainable values within advergames could also be part of games design.

To conclude, the main contribution of this paper is in developing the idea that visual familiarity could influence consumer behaviour when investigating cross-cultural advergame design. If a particular culture is familiar with the visual semiotics used in the game, then it is more likely to reach a wider audience. This means that if advergames can be tailored for different countries, they could carry more impact. Future work needs to explore all the nuances such as design, culture, immersion and consumer attitudes in more depth and detail, adding to this exploratory study a wider understanding of the use of familiar elements in games.

\section{Acknowledgements}

Vanissa Wanick gratefully acknowledges Coordenação de Aperfeiçoamento de Pessoal de Nível Superior (CAPES), Brazil, (number: 9520-13-9) for her PhD studentship. The authors 
also thank the reviewers and editors for insightful comments on the paper during the revision stage.

\section{Appendix A}

\section{Questionnaire}

a) Section 1: Questions about you

1- What age are you? 18-25 / 26-35 / 36-40 / over 40

2- What is your Gender? Female / Male / Other

3- Level of Education? High School / Undergraduate / Master's Degree /PhD

4- Which country are you from?

5- $\quad$ State/County?

6- How often do you play games? (1=never, $7=$ daily $)$

7- $\quad$ Are you colour blind?

8- $\quad$ My attitude towards the Fairtrade mark is: (1=bad, 7=good; $1=$ unfavourable, $7=$ favourable; $1=$ negative, $7=$ positive)

b) Section 2: Gameplay

To continue with this research, please click in the link below to play the game! http://do-doc-ahedron.co.uk/research/uk/onossocafezinho

How to play: click on the red beans and click on the buttons on the left to get more points!

Be careful with the time!

c) Section 3: Now that you've played the game, please answer the following questions (1= strongly disagree, $7=$ strongly agree).

9- $\quad$ I enjoyed playing the game

10- I liked the game 
11- I would play this game again

12- $\quad$ The graphics were appropriate for the type of game

13- I did not like the music in the game

14- The graphics of the game supported the scenario

15- The graphics and sound effects of the game supported each other

16- $\quad$ The sound of the game affected the way I was playing

17- The game was unfair

18- I understood the rules of the game

19- $\quad$ The game was challenging

20- $\quad$ The game was difficult

21- The game scenario was interesting

22- I did not like the scenario of the game

23- I felt like sharing the game with my friends and family

24 - The game theme was familiar to me

25- The game narrative provided me a sense of familiarity with the game theme

26 - I am familiar with the brand

27- The game graphics (icons, symbols and objects) were familiar to me

28- The game scenario provided me a sense of familiarity with the game's theme

29- The game colour scheme provided me a sense of familiarity with the game's theme

30- The music and the sound effects provided me a sense of familiarity with the game's theme

31- The rules of the game were familiar to me

32- How did you feel after playing the game? (1=passive, $7=$ active; $1=$ mellow, $7=$ fired up; $1=$ low energy, 7= high energy) 
33- My attitude towards the Fairtrade mark is: $(1=$ bad, $7=$ good; $1=$ unfavourable, $7=$ favourable; $1=$ negative, $7=$ positive)

34- $\quad$ I thought that the game was: $(1=$ not humorous, $7=$ humorous; $1=$ not funny, $7=$ funny; $1=$ not amusing, $7=$ amusing)

35- Any other comments?

\section{Appendix B}

Table B-1 Summary of differences and similarities found after the study

\begin{tabular}{|l|l|l|}
\hline Factors & Brazil/UK comparison & Managerial implications \\
gameplay & $\begin{array}{l}\text { Both Brazilians and British had } \\
\text { the same level of game } \\
\text { enjoyment (no differences) }\end{array}$ & $\begin{array}{l}\text { Other aspects of advergame design } \\
\text { could be localised; visual elements } \\
\text { maght not be enough to trigger } \\
\text { game enjoyment }\end{array}$ \\
\hline Visual familiarity & $\begin{array}{l}\text { Brazilians were more familiar } \\
\text { with visual elements (game } \\
\text { scenario, colour scheme and } \\
\text { game objects) within the } \\
\text { advergame }\end{array}$ & $\begin{array}{l}\text { Designing advergames with } \\
\text { familiar visual elements is crucial } \\
\text { for advergame effectiveness in } \\
\text { Brazil; semiotics can be a strategic }\end{array}$ \\
\hline Brand familiarity & $\begin{array}{l}\text { British were more familiar } \\
\text { with the brand }\end{array}$ & $\begin{array}{l}\text { Brand familiarity could have } \\
\text { cultures }\end{array}$ \\
familiarity in attitudes towards the
\end{tabular}




\begin{tabular}{|c|c|c|}
\hline & & $\begin{array}{l}\text { brand; studies with unfamiliar } \\
\text { brands and other aspects like } \\
\text { country-of-origin (COI) are } \\
\text { encouraged to understand the } \\
\text { effectiveness of visual familiarity }\end{array}$ \\
\hline Humour & $\begin{array}{l}\text { Brazilians found the game } \\
\text { more humorous }\end{array}$ & $\begin{array}{l}\text { Developers and marketers could } \\
\text { use visual familiarity to trigger } \\
\text { humorous attitudes in Brazil (and } \\
\text { other high-context cultures) }\end{array}$ \\
\hline Arousal & $\begin{array}{l}\text { Both British and Brazilians had } \\
\text { the same level of arousal }\end{array}$ & $\begin{array}{l}\text { Culture might not mediate arousal } \\
\text { attitudes and visual familiarity } \\
\text { does not influence arousal; other } \\
\text { factors might influence this like } \\
\text { game enjoyment, for instance }\end{array}$ \\
\hline $\begin{array}{l}\text { Intentions to } \\
\text { share }\end{array}$ & $\begin{array}{l}\text { Both British and Brazilians had } \\
\text { the same intentions to share } \\
\text { the advergame }\end{array}$ & $\begin{array}{l}\text { Culture might not mediate this and } \\
\text { visual familiarity does not } \\
\text { influence intentions to share } \\
\text { advergames; thus, other factors } \\
\text { like game enjoyment and arousal } \\
\text { might trigger sharing attitudes }\end{array}$ \\
\hline
\end{tabular}




\begin{tabular}{|c|c|c|}
\hline Viral/Sharing & $\begin{array}{l}\text { Both British and Brazilians } \\
\text { shared the advergame with the } \\
\text { same intensity }\end{array}$ & $\begin{array}{l}\text { Culture might not mediate this and } \\
\text { visual familiarity does not } \\
\text { influence advergame sharing in } \\
\text { social media; thus, other factors } \\
\text { like game enjoyment and arousal } \\
\text { might trigger this behaviour }\end{array}$ \\
\hline $\begin{array}{l}\text { Attitudes towards } \\
\text { the brand (after } \\
\text { gameplay) }\end{array}$ & $\begin{array}{l}\text { Comparing before-after } \\
\text { gameplay attitudes: British had } \\
\text { less favourable attitudes } \\
\text { towards the brand, whereas } \\
\text { Brazilians had more favourable } \\
\text { attitudes towards the brand } \\
\text { after gameplay }\end{array}$ & $\begin{array}{l}\text { Visual familiarity could influence } \\
\text { attitudes towards the brand; } \\
\text { developers and marketers could } \\
\text { use this as a strategy for } \\
\text { advergame effectiveness in } \\
\text { cultures like Brazil (high-context) }\end{array}$ \\
\hline
\end{tabular}

\section{References}

[1] G. Georgieva, S. Arnab, M. Romero, S. de Freitas, Transposing freemium business model from casual games to serious games, Entertain. Comput. 9-10 (2015) 29-41. doi:10.1016/J.ENTCOM.2015.07.003.

[2] M. Svahn, Future-proofing advergaming: a systematisation for the media buyer, in: Proc. Second Australas. Conf. Interact. Entertain., Creativity \& Cognition Studios Press, Sydney, Australia, 2005: pp. 187-191. http://dl.acm.org/citation.cfm?id=1109180.1109210 (accessed November 4, 2013).

[3] M.K.J. Waiguny, M.R. Nelson, R. Terlutter, Entertainment matters! The relationship between challenge and persuasiveness of an advergame for children, J. Mark. Commun. 18 (2012) 69-89. doi:10.1080/13527266.2011.620766. 
[4] M. Deuze, Living in Media and the Future of Advertising, J. Advert. 45 (2016) 326333. doi:10.1080/00913367.2016.1185983.

[5] R. Terlutter, M.L. Capella, The Gamification of Advertising: Analysis and Research Directions of In-Game Advertising, Advergames, and Advertising in Social Network Games, J. Advert. 42 (2013) 95-112. doi:10.1080/00913367.2013.774610.

[6] G. Hofstede, Culture's Consequences: Comparing Values, Behaviors, Institutions and Organizations Across Nations, SAGE, 2001.

[7] J.-C. Usunier, J.A. Lee, Marketing Across Cultures, 4th ed., Financial Times Prentice Hall, Harlow, 2005.

[8] R. Terlutter, S. Diehl, B. Mueller, International Advertising and Communication, DUV, 2006. doi:10.1007/3-8350-5702-2.

[9] M. Hermeking, Culture and Internet Consumption : Contributions from CrossCultural Marketing and Advertising Research, J. Comput. Commun. Cult. 11 (2006) 192-216. doi:10.1111/j.1083-6101.2006.00010.x.

[10] McKinsey Global Institute, Can Latin America reignite growth by connecting with consumers? | McKinsey \&amp; Company, McKinsey Glob. Inst. (2016). http://www.mckinsey.com/global-themes/employment-and-growth/can-latinamerica-reignite-growth-by-connecting-with-consumers (accessed January 29, 2017).

[11] Newzoo, Brazil Dominates the Fast Growing LATAM Games Market, Brazil Domin. Fast Grow. LATAM Games Mark. (2014). http://www.newzoo.com/news/globalcollect-newzoo-brazil-dominates-fastgrowing-latam-games-market/ (accessed November 30, 2015).

[12] S. Shavitt, a. Y. Lee, C.J. Torelli, Cross-cultural issues in consumer behavior, in: Front. Soc. Psychol., 2009: pp. 237-250. doi:10.4324/9781441605283.

[13] M.D. Hernandez, S. Chapa, M.S. Minor, C. Maldonado, HISPANIC ATTITUDES TOWARD ADVERGAMES : A PROPOSED MODEL OF THEIR ANTECEDENTS, J. Interact. Advert. 5 (2004) 74-83. 
[14] B.M. Sukoco, W.-Y. Wu, The effects of advergames on consumer telepresence and attitudes: A comparison of products with search and experience attributes, Expert Syst. Appl. 38 (2011) 7396-7406. doi:10.1016/j.eswa.2010.12.085.

[15] V. Cauberghe, P. De Pelsmacker, Advergames, J. Advert. 39 (2010) 5-18. doi:10.2753/JOA0091-3367390101.

[16] S. Dahl, L. Eagle, C. Báez, Analyzing advergames: active diversions or actually deception. An exploratory study of online advergames content, Young Consum. Insight Ideas Responsible Mark. 10 (2009) 46-59. doi:10.1108/17473610910940783.

[17] A. Shelton, M.L. Gross, Advergames and the effects of game-product congruity, Comput. Human Behav. 26 (2010) 1259-1265. http://www.sciencedirect.com/science/article/pii/S0747563210000804 (accessed October 24, 2013).

[18] T. Winkler, K. Buckner, Receptiveness of Gamers to Embedded Brand Messages in Advergames : Attitudes towards Product Placement, J. Interact. Advert. 7 (2006) 37 46.

[19] M.K.J. Waiguny, M.R. Nelson, B. Marko, How Advergame Content Influences Explicit and Implicit Brand Attitudes: When Violence Spills Over, J. Advert. 42 (2013) 155 169. doi:10.1080/00913367.2013.774590.

[20] M. Lee, S. Youn, Leading National Advertisers' Uses of Advergames, J. Curr. Issues Res. Advert. 30 (2008) 1-13. doi:10.1080/10641734.2008.10505243.

[21] D. Johnson, J. Wiles, Effective affective user interface design in games., Ergonomics. 46 (2003) 1332-45. doi:10.1080/00140130310001610865.

[22] M.D. Hernandez, A Model of Flow Experience as Determinant of Positive Attitudes Toward Online Advergames, J. Promot. Manag. 17 (2011) 315-326. doi:10.1080/10496491.2011.596761.

[23] T. Bakalash, H. Riemer, Exploring Ad-Elicited Emotional Arousal and Memory for the Ad Using fMRI, J. Advert. 42 (2013) 275-291. doi:10.1080/00913367.2013.768065. 
[24] K. Wise, P. Bolls, H. Kim, A. Venkararaman, R. Meyer, Enjoyment of Advergames and Brand Attitudes: The Impact of Thematic Relevance, J. Interact. Advert. (2008).

[25] S.Y. Lee, F. Shen, Joint Advertising and Brand Congruity: Effects on Memory and Attitudes, J. Promot. Manag. 15 (2009) 484-498. doi:10.1080/10496490903276874.

[26] J. Wuts, O. Person, E. Jan Hultink, M. Brands, Next-Level Branding: Digital Brand Fit in Video-Game Design, Des. Manag. Rev. 23 (2012) 74-82. doi:10.1111/j.19487169.2012.00173.x.

[27] R.J. Faber, M. Lee, Effects of Product Placement in On-Line Games on Brand Memory: A Perspective of the Limited-Capacity Model of Attention, J. Advert. 36 (2008) 75-90. doi:10.2753/JOA0091-3367360406.

[28] J. Martí-Parreño, J. Aldás-Manzano, R. Currás-Pérez, I. Sánchez-García, Factors contributing brand attitude in advergames: Entertainment and irritation, J. Brand Manag. 20 (2012) 374-388. doi:10.1057/bm.2012.22.

[29] A. Besharat, A. Kumar, J.R. Lax, E.J. Rydzik, Leveraging Virtual Attribute Experience in Video Games to Improve Brand Recall and Learning, J. Advert. 42 (2013) 170-182. doi:10.1080/00913367.2013.774593.

[30] S. Okazaki, M.J. Yagüe, Responses to an advergaming campaign on a mobile social networking site: An initial research report, Comput. Human Behav. 28 (2012) 78-86. doi:10.1016/j.chb.2011.08.013.

[31] D. Luna, S.F. Gupta, An integrative framework for cross-cultural consumer behavior, Int. Mark. Rev. 18 (2001) 45-69. doi:10.1108/02651330110381998.

[32] R. Heimgartner, Intercultural user interface design - Culture-centered HCI design Cross-cultural user interface design: Different terminology or different approaches?, Lect. Notes Comput. Sci. (Including Subser. Lect. Notes Artif. Intell. Lect. Notes Bioinformatics). 8013 LNCS (2013) 62-71. doi:10.1007/978-3-642-39241-2-8.

[33] A. Marcus, E.W. Gould, Crosscurrents: cultural dimensions and global Web userinterface design, Interactions. 7 (2000) 32-46. doi:10.1145/345190.345238.

[34] P. Bourges-Waldegg, S.A.R. Scrivener, Meaning, the central issue in cross-cultural HCI 
design, Interact. Comput. 9 (1998) 287-309. doi:10.1016/S0953-5438(97)00032-5.

[35] I. Gasparini, M.S. Pimenta, J.P.M. De Oliveira, Vive la différence!: a survey of culturalaware issues in HCI, in: 10th Brazilian Symp. Hum. Factors Comput. Syst. 5th Lat. Am. Conf., Brazilian Computer Society, Porto de Galinhas, PE, Brazil, 2011: pp. 13-22. http://dl.acm.org/citation.cfm?id=2254436.2254442 (accessed February 24, 2016).

[36] V. Evers, D. Day, The Role of Culture in Interface Acceptance, in: S. Howard, J. Hammond, G. Lindgaard (Eds.), Human-Computer Interact. INTERACT '97, Springer US, Boston, MA, 1997: pp. 260-267. doi:10.1007/978-0-387-35175-9_44.

[37] N. Crilly, J. Moultrie, P.J. Clarkson, Seeing things: consumer response to the visual domain in product design, Des. Stud. 25 (2004) 547-577. doi:10.1016/j.destud.2004.03.001.

[38] K. Edwards, Culturalization: The Geopolitical and Cultural Dimension of Game Content, (2011).

[39] R. Khaled, R. Biddle, J. Noble, P. Barr, R. Fischer, Persuasive interaction for collectivist cultures, in: Seventh Australas. User Interface Con- Ference (AUIC 2006), Australian Computer Society, Inc., Hobart, Australia, 2006: pp. 73-80. http://dl.acm.org/citation.cfm?id=1151758.1151767 (accessed May 18, 2015).

[40] S. Hall, Cultural studies and its theoretical legacies, in: Stuart Hall Crit. Dialogues Cult. Stud., 1996: pp. 261-274.

[41] G. Freyre, The Masters and the Slaves: A Study in the Development of Brazilian Civilization, Random House, 1956.

[42] F. Azevedo, Brazilian culture : an introduction to the study of culture in Brazil, Hafner Pub. Co, New York, 1971.

[43] E.M. Soriano de Alencar, N.P. Braga, R.M. Prado, J.F. Chagas-Ferreira, Spirituality and creativity of indigenous societies in Brazil and their legacy to Brazilian culture and creative giftedness, Gift. Educ. Int. 32 (2016) 224-231. doi:10.1177/0261429415602581.

[44] E.T. Hall, Beyond culture, Anchor, New York, 1981. 
[45] E. Kaynak, A. Kara, Reinforcing Cultural Identity by Appealing to Local Cultural Cues: National Identity Formation and Consumption in High-Context Cultures, J. Promot. Manag. 19 (2013) 86-113. doi:10.1080/10496491.2012.736464.

[46] E. Calvillo Gamez, P. Cairns, A. Cox, From the Gaming Experience to the Wider User Experience, People Comput. (2009) 520-523. http://discovery.ucl.ac.uk/103944/.

[47] C.S. Gulas, M.G. Weinberger, Humor in Advertising: A Comprehensive Analysis, M.E. Sharpe, 2006.

https://books.google.com/books?hl=en\&lr=\&id=DMFS2GsTd04C\&pgis=1 (accessed October 27, 2015).

[48] D.M. Grigorovici, C. Constantin, EXPERIENCING INTERACTIVE ADVERTISING BEYOND RICH MEDIA: IMPACTS OF AD TYPE AND PRESENCE ON BRAND EFFECTIVENESS IN 3D GAMING IMMERSIVE VIRTUAL ENVIRONMENTS, J. Interact. Advert. 5 (2004) 22-36. http://jiad.org/download5fb3.pdf?p=53.

[49] M.D. Hernandez, M.S. Minor, Investigating the effect of arousal on brand memory in advergames: Comparing qualitative and quantitative approaches, Qual. Mark. Res. An Int. J. 14 (2011) 207-217. doi:10.1108/13522751111120701.

[50] J. Berger, Arousal increases social transmission of information., Psychol. Sci. a J. Am. Psychol. Soc. / APS. 22 (2011) 891-893. doi:10.1177/0956797611413294.

[51] A. Waern, J. Back, Experimental Game Design, in: Game Res. Methods An Overv., 2015.

[52] K.L. Norman, GEQ (Game Engagement/experience questionnaire): A review of two papers, Interact. Comput. 25 (2013) 278-283. doi:10.1093/iwc/iwt009.

[53] Fairtrade Foundation, Unlocking the Power of the many, 2013.

[54] EUROPEAN COFFEE FEDERATION (ECF), European Coffee Report, 2014. http://www.ecf-coffee.org/images/European_Coffee_Report_2013-14.pdf (accessed August 1, 2016).

[55] Fairtrade Foundation, Fairtrade and coffee, 2012. http://www.fairtrade.net/fileadmin/user_upload/content/2009/resources/2012_F 
airtrade_and_coffee_Briefing.pdf.

[56] T.J. Madden, K. Hewett, M.S. Roth, J. Madden, Managing Images in Different Cultures: A Cross-National Study of Color Meanings and Preferences, J. Int. Mark. 8 (2000) 90107.

[57] M.M. Aslam, Are You Selling the Right Colour? A Cross-cultural Review of Colour as a Marketing Cue, J. Mark. Commun. 12 (2006) 15-30.

doi:10.1080/13527260500247827.

[58] C.S. Peirce, Peirce on signs: Writings on semiotic, UNC Press Books, 1991.

[59] L. Niemeyer, Elementos de Semiótica aplicados ao design, 2AB, 2003.

[60] R. Beasley, M. Danesi, Persuasive Signs: The Semiotics of Advertising, Walter de Gruyter, 2002. http://books.google.com/books?hl=en\&lr=\&id=xa0XWi1kg60C\&pgis=1 (accessed February 1, 2014).

[61] C.S. de Souza, The semiotic engineering of user interface languages, Int. J. Man. Mach. Stud. 39 (1993) 753-773.

[62] A.E.P. Poubel, T.E.J. Valente, P.M.C. Garone, U. Universidade, E. Santo, D.D.D. Industrial, D.C.S. Peirce, 0 processo semiótico de criação de um personagem de jogo, in: 2012: pp. 208-214.

[63] D.D. Muehling, R.N. Laczniak, Advertising's Immediate and Delayed Influence on Brand Attitudes: Considerations across Message-Involvement Levels, J. Advert. 17 (1988) 23-34. doi:10.1080/00913367.1988.10673126.

[64] A. Chattopadhyay, K. Basu, Humor in Advertising: The Moderating Role of Prior Brand Evaluation, J. Mark. Res. (1990). http://www.jstor.org/stable/3172631?seq=1\#page_scan_tab_contents (accessed October 28, 2015).

[65] I. Ajzen, The Theory of Planned Behaviour, Organ. Behav. Hum. Decis. Process. 50 (1991) 179-211. doi:10.1016/j.drugalcdep.2011.10.011.

[66] J. Berger, K.L. Milkman, What Makes Online Content Viral?, J. Mark. Res. 49 (2012) 
192-205. doi:10.1509/jmr.10.0353.

[67] J. Chakraborty, A.F. Norcio, Cross Cultural Computer Gaming, in: Int. Des. Glob. Dev., 2009: pp. 13-18. doi:10.1007/978-3-642-02767-3_2.

[68] National Consumer Council, S.D. Commission, I will if you will. Towards sustainable consumption, 2006.

[69] R. Smithers, Global Fairtrade sales reach £4.4bn following 15\% growth during 2013 | Global development | The Guardian, (2014). https://www.theguardian.com/globaldevelopment/2014/sep/03/global-fair-trade-sales-reach-4-billion-following-15per-cent-growth-2013 (accessed September 2, 2017).

[70] I. Vermeir, W. Verbeke, Sustainable food consumption: Exploring the consumer “attitude - Behavioral intention” gap, J. Agric. Environ. Ethics. 19 (2006) 169-194. doi:10.1007/s10806-005-5485-3.

[71] C. Jennett, A.L. Cox, P. Cairns, S. Dhoparee, A. Epps, T. Tijs, A. Walton, Measuring and defining the experience of immersion in games, Int. J. Hum. Comput. Stud. 66 (2008) 641-661. http://www.sciencedirect.com/science/article/pii/S1071581908000499 (accessed November 12, 2013).

[72] R. Khaled, P. Barr, R. Biddle, R. Fischer, J. Noble, Game design strategies for collectivist persuasion, in: Proc. 2009 ACM SIGGRAPH Symp. Video Games - Sandbox '09, ACM Press, New York, New York, USA, 2009: p. 31.

doi:10.1145/1581073.1581078.

[73] A. Ranchhod, C. Gurau, E. Marandi, Brand names and global positioning, Mark. Intell. Plan. 29 (2011) 353-365. doi:10.1108/02634501111138536.

[74] E. Minton, C. Lee, U. Orth, C. Kim, L. Kahle, Sustainable Marketing and Social Media: A Cross-Country Analysis of Motives for Sustainable Behaviors, J. Advert. 41 (2013) 37-41. doi:10.2753/JOA0091-3367410405. 